\title{
Frequency regulation of multiple asynchronous grids using adaptive droop in high-voltage direct current system
}

\author{
Mehedi Hassan ${ }^{1}$, Rakibuzzaman Shah ${ }^{2}$, Jahangir Hossain ${ }^{3}$ \\ ${ }^{1}$ School of Engineering, Macquarie University, Macquarie Park, NSW 2113, Australia \\ ${ }^{2}$ School of Science Engineering and Information Technology, Federation University, Mt Helen, VIC 3350, Australia \\ ${ }^{3}$ School of Electrical and Data Engineering, University of Technology Sydney, NSW 2007, Australia \\ 凶E-mail: mehedi.hassan@hdr.mq.edu.au
}

\begin{abstract}
Frequency stability control in multiple asynchronous grids is a challenging and complex issue. An adaptive droop control strategy to improve the frequency regulation of asynchronous AC areas connected by a multi-terminal DC grid is proposed here. The droop coefficients are adjusted to share the active power adaptively among multiple asynchronous AC grids based on the characteristics of frequency deviation and rate of change of frequency. This results in a cogent allocation of imbalance power in multiple asynchronous grids from the frequency variation perspective. The performance of the proposed scheme is evaluated in a modified multi-machine power system using DIgSILENT Power Factory. Simulation results under significant frequency disturbances caused by credible contingencies are presented to demonstrate the effectiveness of the proposed approach. It is found that the proposed adaptive control ensures an excellent and robust frequency response under different operative conditions.
\end{abstract}

\section{Introduction}

Multi-terminal high-voltage direct current (MT-HVDC) system is a promising alternative to interconnect asynchronous $\mathrm{AC}$ grids and renewable generations such as offshore wind systems. With the immense evolution of semiconductor technology, an modular multilevel converter (MMC)-HVDC system offers a cost-effective transmission of bulk power over long distances with higher efficiency. This paves the way for MMC-HVDC transmission to participate in energy trading markets with the capability of providing ancillary services [1]. In terms of frequency regulation, the HVDC link permits to exchange the online capacity of primary reserves amidst the interconnected asynchronous AC grids followed by a large disturbance [1-4]. This functionality of the HVDC system plays a significant role in AC grids with a lower spinning reserve due to the successive retirement of conventional power plants and the integration of non-dispatchable renewable generators.

Due to the power-electronic interface, an MMC-HVDC link decouples the power system into multiple asynchronous AC areas. Thereby, frequency excursion succeeded by a grid disturbance in one AC area does not affect the other adjacent AC system. However, to arrest the deviation of frequency in $\mathrm{AC}$ grids, historically, the generators are equipped with governor control mechanisms. A governor regulates the active power of the generator by controlling its speed in response to locally measured changes in frequency. Thus, the frequency deviation of the grid is arrested within a few seconds with the adjustment in power imbalance, known as the primary frequency response (PFR). To do so, the active power delivered must have some marginal value that is known as primary reserve. The provision of primary reserve bears a considerable amount of operational costs [5]. In the system where the non-synchronous generators' participation is significantly high, the system operators begin to experience concern regarding the frequency regulation due to the low primary reserve. Therefore, most of the power systems in Europe, for example, Eirgrid and other Nordic operators require nonsynchronous generators including HVDC to participate in frequency regulation [6].

Most of the prior studies on the frequency regulation scheme have exclusively focused on the HVDC link with offshore wind farms [7-12]. Prior researches in this domain have used the voltage source converter (VSC)-HVDC system capacitor energy to emulate inertia. Recently, the temperature constrained overloading of the MMC-HVDC system has been reported for inertia support of the $\mathrm{AC}$ grid [1]. However, the amount of inertial energy obtained from MMC overloading may not be sufficient to support adjacent AC grids during large disturbances. A few papers in the literature demonstrate the approach of frequency support through asynchronous AC grids connected by HVDC link(s) [6, 13-16]. A synchronous generator emulation control (SGEC) strategy is proposed in [13] to share the power reserve between two asynchronous AC grids connected by a point-to-point HVDC link. From the analysis in [13], it is apparent that the VSC-HVDC link can effectively balance the frequencies of the interconnected grids under smaller disturbances. However, this control method may not ensure the required frequency regulation support under significant contingencies. Furthermore, the research work in [13] is limited to a single infeed HVDC system.

The concept of reserve sharing with a multi-terminal DC (MTDC) grid is also analysed and reported in [6, 14]. The suggested controller in [6] is designed based on the consensus algorithm that controls the frequency of $\mathrm{AC}$ areas by adjusting the DC grid power in a coordinated way. However, to converge the frequency deviations close to each other, all the parameters of $\mathrm{AC}$ areas are assumed to be identical in [6]. The distributed proportional-integral (PI) controller proposed in [14] can converge the AC grid frequencies to the nominal values and stabilise the AC/ MTDC system. However, the proposed method in [14] requires additional communication links from neighbouring asynchronous areas. There are also reliability issues with this communication link.

To reduce the cost and enhance reliability, a selective power route for supporting PFR using the minimum communication is proposed in [15]. With the assistance of voltage and frequency droop, primary frequency support is provided to the asynchronous $\mathrm{AC}$ grids based on the characteristics of the disturbances. However, the control scheme implemented in [15] is not entirely communication free. To avoid the dependency of communication channels, an $V-I-f$-based adaptive droop control (ADC) strategy is established in [16]. The proposed controller in [16] enables the VSC station to regulate the onshore grid frequency by 

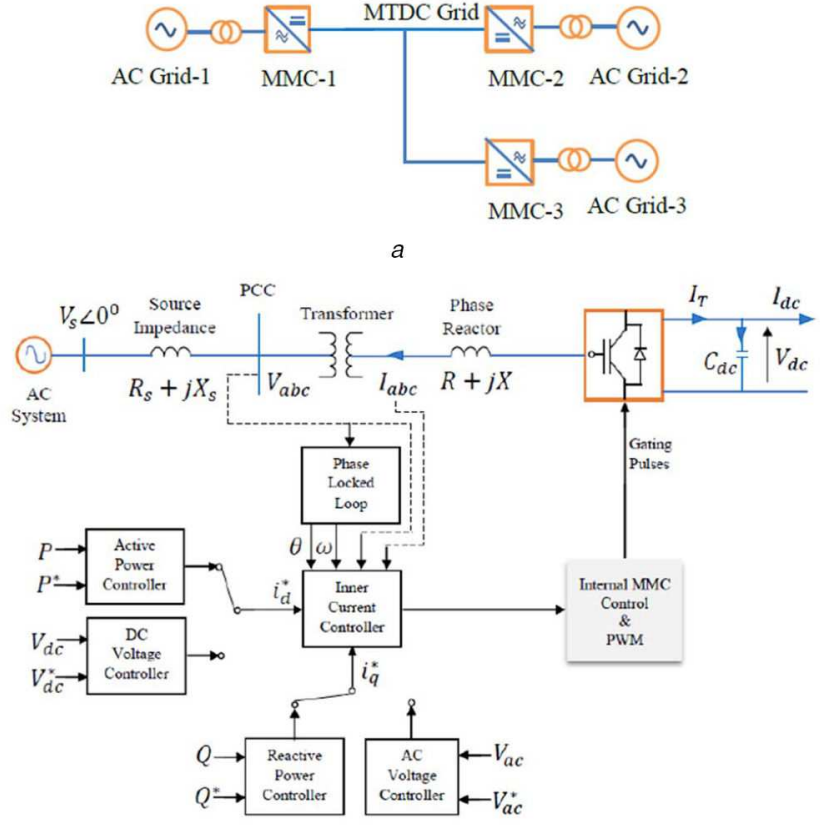

$b$

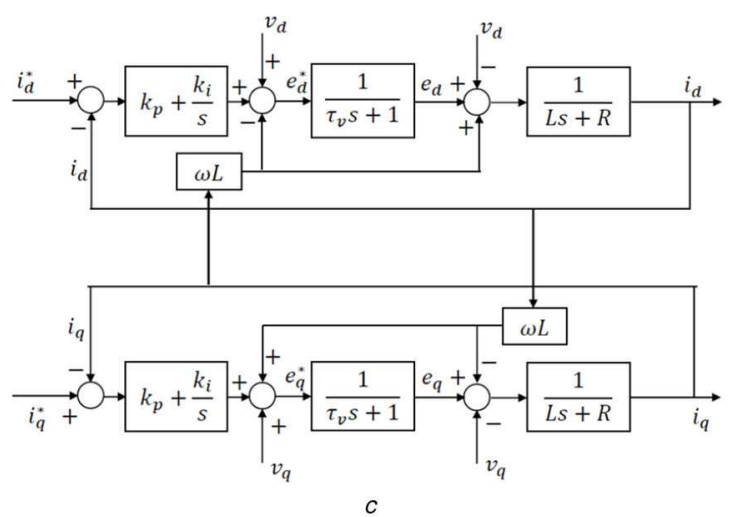

Fig. $1 A C / M T D C$ system configuration and control

(a) Three terminal radial system, (b) MMC-HVDC system control scheme, (c) $d q$ current controller

adjusting the DC voltage reference autonomously. However, the test system considered in [16] has limited scope to represent the after effect of frequency response in supporting AC grids. In conclusion, it is common for a global system that sharing reserves also affects the frequency of the other synchronous areas, which is not properly explored in the aforementioned studies. Supervisory control methods for implementing frequency regulation in a VSCHVDC system are presented in $[2,3,12]$. These proposed methods are based on the communication channel and complex control mechanism for implementing frequency regulation service at the HVDC system.

To overcome the complexities and issues with a communication channel, this paper proposes an improved ADC strategy considering the constraints of the $\mathrm{AC}$ grid frequency response characteristics, i.e. frequency deviation $(\Delta f)$ and rate of change of frequency (RoCoF, $\Delta f$ ). The constraints are used in the proposed scheme due to reasons given below:

(i) In a conventional droop control (CDC) scheme, the values of the droop coefficients are fixed. It is selected based on the respective converter ratings. It does not consider the strength of the AC grid connected with the converters. Hence, irrespective of the nature of the AC network (i.e. strong or weak), the asynchronous grids are supposed to share a fixed and equal amount of power during any frequency disturbance. As a result, sharing the excessive amount of power might cause unacceptable frequency deviation and jeopardise the security of the sending end of the asynchronous grid. Therefore, this paper considers the constraints of frequency deviation in the proposed scheme.

(ii) Followed by a disturbance, the asynchronous AC grid with higher RoCoF value might trigger the protective relay and discontinue the system operation. It may affect the power sharing of asynchronous grids. Hence, the RoCoF constraint is also used in the proposed scheme.

This paper proposes an adaptive and communication channel free control strategy for asynchronous grids connected via MTDC to enhance the overall frequency response without deteriorating the frequency characteristics of the adjacent $\mathrm{AC}$ systems. Compared with previous work, the main features of the proposed work are as follows:

(i) The power sharing among asynchronous AC grids via MTDC for frequency stability is studied.

(ii) Adaptive control is proposed where only local measurements are required.

(iii) An adaptive droop scheme by considering the frequency deviation and RoCoF constraints is proposed.

(iv) Comprehensive performance assessment compared to wellreported methods is presented.

The rest of the paper is organised as follows. The AC/MTDC system structure including the basic VSC control mechanism and frequency regulatory standards for the UK system are given in Section 2. The CDC scheme used for frequency regulation is addressed in Section 3. The ADC strategy for effective power sharing and frequency regulation is illustrated in Section 4. Section 5 presents the simulation results and discussions for various contingencies to validate the effectiveness of the proposed controller. Finally, conclusions and future direction of work are given in Section 6 .

\section{System modelling and frequency regulation standards}

The system configuration of the integrated AC/MTDC grid with the typical control structure is briefly presented in this section. The basis of the test $\mathrm{AC}$ system considered here is the representative Great Britain (GB) power system network described briefly in Section 5. Hence, the frequency regulatory framework of the GB system has been considered in this work.

\subsection{System topology}

The system depicted in Fig. $1 a$ is a three-terminal MTDC grid with radial topology. Three asynchronous $\mathrm{AC}$ grids are interconnected via an MTDC grid. The MTDC grid consists of three MMC-VSC systems. Each converter is connected to the adjacent AC grid at the point of common coupling (PCC) through a converter transformer and an interfacing phase reactor. The local $\mathrm{AC}$ grid seen by the converter can be represented by a Thevenin equivalent circuit of a constant $\mathrm{AC}$ voltage source with series impedance $\left(R_{\mathrm{s}}+\mathrm{j} X_{\mathrm{s}}\right)$ as shown in Fig. $1 b$. The equivalent resistance and inductance of the converter transformer and MMC arm reactors are replicated by $R$ and $L$, respectively. $C_{\mathrm{dc}}$ is the DC link equivalent capacitance formed by the MMC which employed sub-module (SM) capacitors.

\subsection{Basic control structure}

The decoupled vector control known as $d q$ control scheme is the widely used technique in a VSC-HVDC station. The control system illustrated in Fig. $1 b$ typically maintains a hierarchical model of two PI control loops. In the cascade structure, the inner current control loop responds faster than the outer control loop. An inner current control loop is implemented in the synchronously rotating $d q$ reference frame at a given frequency $\omega$. The threephase AC quantities $\left(V_{a b c}, I_{a b c}\right)$ are transformed into twocomponent DC quantities $\left(v_{d q}, i_{d q}\right)$ using $d q$ transformation. Therefore, the dynamic model of the system can be expressed as in (1):

IET Gener. Transm. Distrib., 2020, Vol. 14 Iss. 7, pp. 1389-1399 (C) The Institution of Engineering and Technology 2020 


$$
\left[\begin{array}{c}
e_{d} \\
e_{q}
\end{array}\right]=\left[\begin{array}{l}
v_{d} \\
v_{q}
\end{array}\right]+R\left[\begin{array}{l}
i_{d} \\
i_{q}
\end{array}\right]+L \frac{\mathrm{d}}{\mathrm{d} t}\left[\begin{array}{c}
i_{d} \\
i_{q}
\end{array}\right]+\omega L\left[\begin{array}{cc}
0 & -1 \\
1 & 0
\end{array}\right]\left[\begin{array}{c}
i_{d} \\
i_{q}
\end{array}\right]
$$

In (1), $e_{d q}$ and $v_{d q}$ refer to the converter internal voltage and PCC bus voltage, respectively. The illustrative structure of the inner current controller is shown in Fig. 1c. The inner loops track current references $\left(i_{d}^{*}, i_{q}^{*}\right)$ by PI controllers and adopt compensations by employing feed-forward voltage terms $\left(v_{d}, v_{q}\right)$ and current decoupling terms $\left(\omega L i_{q}, \omega L i_{d}\right)$.

The outer controllers provide current references to the inner current control loops. The outer loop controls either DC voltage $\left(V_{\mathrm{dc}}\right)$ or active power $(P)$ by providing the $d$-axis reference current $\left(i_{d}^{*}\right)$ and AC voltage $\left(V_{\mathrm{ac}}\right)$ or reactive power $(Q)$ by providing a $q$ axis reference current $\left(i_{q}^{*}\right)$.

In the studied MTDC system, MMC-1 station operates in $\left(V_{\mathrm{dc}}-Q\right)$ control mode. It controls the DC grid voltage to maintain the active power balance in the MTDC grid. On the other hand, MMC-2 and MMC-3 stations control the active and reactive power flow by operating in $(P-Q)$ control mode with the DC voltage droop.

\subsection{Frequency regulatory framework}

Due to an imbalance between power generation and demand, the frequency of a power system deviates from its nominal value (e.g. $50.0 \mathrm{~Hz}$ in Europe and the UK). For ensuring the power system's security and reliability, the transmission system operator (TSO) is responsible to maintain their frequency regulatory standards based on certain grid codes such as the framework of the European Network of Transmission System Operators for Electricity (ENTSO-E) and National Grid Codes. During the short-term transient period, the frequency behaviour of the power system can be analysed by the key indicators such as frequency nadir and RoCoF.

Frequency nadir $(\mathrm{Hz})$ is the maximum frequency excursion during the transient period before the frequency starts to recover and settles down to a fixed value [17]. To arrest the frequency deviation going beyond the permissible limit of $\pm 500 \mathrm{mHz}$, generating units are supposed to provide PFR within a few seconds $(10-30 \mathrm{~s})$ [18]. To ensure minimum PFR, each generator is instructed to maintain frequency droop value within the range of $2-$ $12 \%$ that results in $1.5-10 \%$ change of active power participation [19].

The capability of providing frequency response is a mandatory requirement for all generating units under the agreement of National Grid in the UK [19]. The TSO reviews its reserve responsibility annually as in (2) [19]:

$$
\mathrm{TSO} R \mathrm{R}=\frac{\left(G_{\mathrm{TSO}}+L_{\mathrm{TSO}}\right)}{\left(G_{\mathrm{Sys}}+L_{\mathrm{Sys}}\right)} \times(\text { System RR })
$$

In (2), $G$ and $L$ define the net generation and net load over the period of 1 year, respectively. The reserve requirement is denoted by RR.

The TSOs can exchange a maximum of $30 \%$ of the total reserve responsibility outside their own operating regions [19]. The service of providing PFR is remunerated depending upon either the headroom reserved or the amount of energy delivered [19].

$\mathrm{RoCoF}(\mathrm{Hz} / \mathrm{s})$ is an index that depicts how fast the frequency changes succeeding a major disturbance. According to the grid code of the UK, the maximum allowable RoCoF for the GB system is $0.5 \mathrm{~Hz} / \mathrm{s}$ followed by a large disturbance [20]. However, crossing the limit of RoCoF beyond the range of -2.5 to $+2.5 \mathrm{~Hz} / \mathrm{s}$ forces the HVDC network to be disconnected instantly [20].

\section{Supplementary controller for frequency regulation}

Due to the fast-responsive characteristics of MMCs, the MTDC system with supplementary controllers can provide primary frequency support by sharing the reserved power of asynchronous

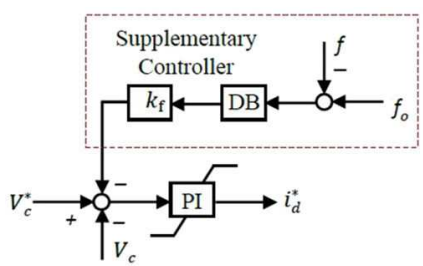

a

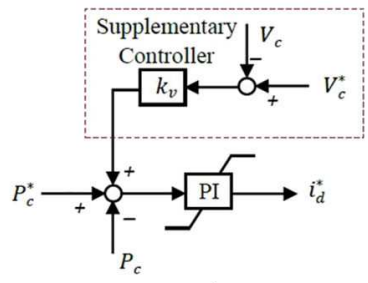

$b$

Fig. 2 Supplementary control scheme

(a) $V_{\mathrm{c}}$ versus $f$ droop control block of DC/AC MMC, (b) $P_{c}$ versus $V_{\mathrm{c}} \mathrm{CDC}$ block

AC grids. This section describes the supplementary control scheme to implement the frequency support mechanism in AC/MTDC interconnections.

\subsection{Control of DC-AC MMC}

In order to maintain the active power balance in an MT-HVDC system, a DC-AC MMC (Inverter) is commonly equipped with a DC voltage controller. A conventional droop i.e. DC voltage versus power is generally used in the DC grid. The generic DC droop control can be expressed as in (3):

$$
V_{c}^{*}=V_{c}^{0}-k_{p}\left(P_{c}^{0}-P_{c}\right)
$$

In (3), $k_{p}$ defines the power droop coefficient, and $V_{c}^{0}$ and $P_{c}^{0}$ are the nominal values of DC voltage and power, respectively.

Although this droop may balance the power in a DC system, however, remains non-responsive to the frequency deviation in $\mathrm{AC}$ grids. To address this issue, a supplementary droop controller i.e. DC voltage versus frequency is introduced in the control as shown in Fig. $2 a$. This control regulates the DC voltage reference with the deviation of frequency followed by any major disturbance in $\mathrm{AC}$ grids. This control operation can be expressed as in (4):

$$
V_{c}^{*}=V_{c}^{0}+k_{f}\left(f-f^{0}\right)
$$

In (4), $k_{f}$ is the frequency droop coefficient, $V_{c}^{*}$ is the reference value of DC voltage, and $f^{0}$ is the nominal frequency of an $\mathrm{AC}$ system. Hence, the overall operation of the converter is described in (5):

$$
V_{c}^{*}=V_{c}^{0}-k_{p}\left(P_{c}^{0}-P_{c}\right)+k_{f}\left(f-f^{0}\right)
$$

In order to avoid the performance degradation caused by the coupling between power droop $\left(V_{c}\right.$ versus $\left.P_{c}\right)$ and frequency droop $\left(V_{c}\right.$ versus $\left.f\right)$, one droop would be operated at a time in any given converter. Therefore, converters connected with an asynchronous AC grid are triggered only from normal operating mode (power droop) to the switching mode (frequency droop) followed by the detection of frequency deviation $(|\Delta f|)$ beyond the specific cut-off limit $\left(\mid \Delta f_{\text {col }}\right)$. This implies that (5) will follow (4) with the condition of $|\Delta f|>\mid \Delta f_{\text {col }}$.

Here, the choice of $k_{f}$ may facilitate the inertial support from an MMC-based MTDC system using the stored energy in DC link capacitors. Equating the dynamics of the converter DC voltage with the synchronous machine, the value of aggregated inertia $\left(H_{\mathrm{MMC}}\right)$ and frequency droop value $\left(k_{f}\right)$ can be determined after the mathematical manipulation as follows [21]: 


$$
\begin{gathered}
H_{\mathrm{MMC}}=\frac{\tau_{c}\left(\left(\left(\Delta V_{c} / V_{c}^{0}\right)+1\right)^{2}-1\right)}{2\left(\Delta f / f^{0}\right)} \\
k_{f}=\frac{\Delta V_{c}}{\Delta f}=\frac{2 H_{\mathrm{MMC}}}{C_{\mathrm{dc}} V_{c}^{0}}
\end{gathered}
$$

In (6) and (7), $C_{\mathrm{dc}}=(6 C / N)$ is the equivalent capacitance and $\tau_{c}=\left(C_{\mathrm{dc}} V_{c}^{0} / 2 S_{\mathrm{MMC}}\right)$ is the time constant of the converter capacitor. Moreover, $C$ is the submodule capacitance, $N$ is the number of submodules/arm and $S_{\mathrm{MMC}}$ is the rated power of an MMC.

It is worth noting from (6) and (7) that a wide range of DC voltage variation is required to get the considerable amount of inertia support from an MMC converter station.

The higher values of capacitance may reduce the voltage variation. However, economically feasible sizing for such a capacitor is yet to be available for commercial applications. Henceforth, there should be a well-balanced compromise among these factors to operate the converter within a permissible range of voltage variation and frequency. This will inevitably emulate enough inertia for the asynchronous AC grids within an acceptable limit and convey the information of frequency deviation to the controllers of an $\mathrm{AC} / \mathrm{DC} \mathrm{MMC}$ system.

\subsection{Control of $A C-D C M M C$}

In an MT-HVDC system, AC-DC MMCs (rectifier) are enabled with the power versus DC voltage droop controller. Fig. $2 b$ depicts this CDC scheme that can detect the frequency disturbance of other $\mathrm{AC}$ grids in terms of $\mathrm{DC}$ voltage variations and responds accordingly by supporting imbalanced power. This relation can be represented as in (8):

$$
P_{c}^{*}=P_{c}^{0}-k_{v}\left(V_{c}^{0}-V_{c}\right)
$$

In (8), $k_{v}$ is the traditional voltage droop coefficient which is defined by $k_{v}=\left(1 / k_{p}\right)[10]$ and $P_{c}^{*}$ is the reference value of DC active power.

Considering the $n$ number of converters is responding with the variation of DC voltage, as being equipped with the CDC. Therefore, it brings equal voltage levels at each bus with the assumption of a lossless MT-HVDC grid. This eventually makes DC voltage deviation of the $i$ th converter $\Delta V_{c i}=\Delta V_{c}$, where $i \in\{1,2, \ldots n\}$. Therefore, the power variation of (8) is rewritten as in (9):

$$
\Delta P_{c i}=-k_{v i} \Delta V_{c}
$$

In (9), $\Delta P_{c i}$ is the power contribution of each converter fitted with a CDC.

Due to the power delivery to an asynchronous grid, the frequency response of the supporting/adjacent AC grid deteriorates. Therefore, this must be restricted within permissible limits. Frequency response can be characterised mainly by two indicators. One is the deviation of frequency $(\Delta f)$ and the other is the $\operatorname{RoCoF}(\Delta \dot{f})$. Hence, to secure a reliable power transport, constraints need to be applied on these two properties.

The active power is directly proportional to the frequency deviation and RoCoF that serves to provide the frequency support and emulate inertia, respectively [22]. Hence, the power extracted from a supporting grid is influenced by these two terms: (i) frequency deviation $(\Delta f)$ and (ii) $\operatorname{RoCoF}(\Delta \dot{f})$. This implies the power as a function of two variables as in (10):

$$
\Delta P_{c i}=\Delta P_{c i 1}+\Delta P_{c i 2}=F_{i}(\Delta f, \Delta \dot{f})
$$

In (10), $\Delta P_{c i 1}$ and $\Delta P_{c i 2}$ are the power contributions for $\Delta \dot{f}$ and $\Delta f$, respectively.

Consequently, the additional power in the MT-HVDC grid $\left(\Delta P_{\mathrm{s}}\right)$ due to the grid disturbance is shared by all CDC-driven converters utilising the relation given in (11) and (12):

$$
\begin{gathered}
\Delta P_{\mathrm{s}}=\sum_{i=1}^{n} \Delta P_{c i}=\sum_{i=1}^{n}-k_{v i} \Delta V_{c}=\sum_{i=1}^{n} F_{i}(\Delta f, \Delta \dot{f}) \\
\Delta P_{c i}=\frac{k_{v i}}{\sum_{i=1}^{n} k_{v i}} \Delta P_{\mathrm{s}}
\end{gathered}
$$

In $\mathrm{CDC}$, the droop $\left(k_{v i}\right)$ is a fixed value coefficient that propels every converter to equally share imbalance power. Since, each converter is connected to asynchronous AC grids, therefore extracting an equal amount of power from them might deteriorate the stability of the supporting network. Hence, rather than being uniform, it is worthy for AC grids to participate in imbalance power support in proportion to their spinning reserves maintaining permissible frequency characteristics.

To achieve this function, a constant value of droop in the CDC is reformed to make variable droop $\left(k_{v i}^{\mathrm{ADC}}\right)$ in $\mathrm{ADC}$ depending upon the RoCoF and frequency excursions of the supporting AC grids. This mechanism will be described in detail in the next section.

\section{Adaptive droop controller for frequency regulation}

The conventional supplementary controller uses a fixed value droop coefficient for sharing power among asynchronous grids. This fixed droop control (power versus DC voltage droop) might jeopardise the security of the supporting power grid. To resolve the issue, this section proposes an ADC strategy that would enhance the frequency regulation effectively.

\subsection{Adaptive droop design scheme}

Along with the synchronous power of an AC system, supplementary power pulled in or out of the converter-based AC/MT-HVDC system is utilised for frequency regulation. This implies the swing equation governed by

$$
2 H \dot{f}=P_{\mathrm{e}}+P_{\mathrm{s}}
$$

In (13), $H$ is the total inertia of an AC/MTDC system, $P_{\mathrm{e}}$ is the effective power of a synchronous machine defined as the difference between generated and consumed power, and $P_{\mathrm{s}}$ is the supplementary power of the system.

Owing to the power imbalance $\Delta P$ caused by a large disturbance in the AC grid, the frequency of the network deviates by $\Delta f$, which ultimately transforms (13) as follows:

$$
2 H_{m} \Delta \dot{f}=\Delta P_{\mathrm{e}}+\Delta P_{\mathrm{s}}
$$

In (14), $H_{m}$ is the total inertia of the system after the disturbance.

Hence, the change of generator power $\left(\Delta P_{\mathrm{e}}\right)$ in the affected network and change of supplementary power $\left(\Delta P_{\mathrm{s}}\right)$ of the MTDC grid are combined for balancing the total imbalanced power $(\Delta P)$. That gives

$$
\Delta P_{\mathrm{s}}=\Delta P-\Delta P_{\mathrm{e}}
$$

The supplementary power of an MTDC grid is provided by asynchronous AC grids connected to it. There would be a frequency excursion because of the generation-demand mismatch of the sending end of the asynchronous grid for providing power to the receiving end of the asynchronous grid. This may truncate a large number of units/loads.

To resolve this issue, power extraction from supporting grids should have some restrictions in terms of their frequency response characteristics. Constraints imposed by the RoCoF and frequency nadir of supporting AC grids are the two key characteristics that are considered here.

4.1.1 Constraint and proximity of RoCoF: RoCoF is the slope of the frequency that falls immediately following a large 
disturbance. The post-contingency system inertia $\left(H_{m i}\right)$ of $i$ th asynchronous grid can be approximated as follows [23]:

$$
H_{m i}=\frac{\sum_{j=1}^{r} H_{g j} P_{g}^{\mathrm{M}}}{f^{0}}
$$

In (16), $P_{g}^{\mathrm{M}}$ and $H_{g j}$ are the maximum output power and postcontingency inertia constant of the synchronous generators, respectively, where $j \in\{1,2, \ldots, r\}$ is the number of existing generators in the grid.

After the occurrence of a large frequency disturbance in the AC grid, the $i$ th asynchronous grid provides $\Delta P_{c i 1}$ amount of power to the disturbed grid based on the value of the system inertia estimated by (16). The RoCoF $\left(\Delta \dot{f}_{i}\right)$ of that asynchronous grid can be determined as follows [23]

$$
\Delta \dot{f}_{i}=\frac{\Delta P_{c i 1}}{2 H_{m i}}
$$

Hence, to guarantee the permissible power support, RoCoF of the supporting asynchronous grid must not exceed its maximum limit, that is $\Delta f_{i \max }$. This implicates the constraints as

$$
\Delta \dot{f}_{i}=\frac{\Delta P_{c i 1}}{2 H_{m i}} \leq \Delta \dot{f}_{i \max }
$$

Therefore

$$
\Delta P_{c i 1 \max } \leq 2 H_{m i} . \Delta \dot{f}_{i \max }
$$

It is clear from (18) that the power provided by the network will increase as it moves towards its RoCoF proximity. The highest power will be drawn when it approaches the maximum value of RoCoF for its permissible range. This implies

$$
\Delta P_{c i 1 \max }=2 H_{m i} . \Delta \dot{f}_{i \max }
$$

Thereby, RoCoF is a key factor of an AC grid that affects the proportion of power sharing in an AC-MTDC grid.

\subsubsection{Constraint and proximity of frequency nadir: Frequency} nadir is the minimum point of frequency reaches before the frequency decline is arrested. It is a direct measure of primary frequency reserve regulated by the response of inertia and governor [17].

For the $i$ th asynchronous grid, the sufficient criterion of the primary reserve to confirm the deviation of frequency nadir without exceeding its pre-defined minimum limit $\left(f^{\mathrm{min}}\right)$ can be expressed as [23]

$$
R_{g j i} \leq 2 v_{g j i} \frac{H_{m i} \Delta f_{i}}{\Delta P_{c i 2}}
$$

In (20), $v_{g j i}$ is the maximum ramp rate, $R_{g j i}$ is the primary reserve and $\Delta f_{i}=\left(f^{0}-f^{\mathrm{min}}-f^{\mathrm{db}}\right)$ is the maximum frequency excursion with a frequency dead band $\left(f^{\mathrm{db}}\right)$.

Followed by the large frequency disturbance in an AC grid, the $i$ th asynchronous grid can render $\Delta P_{c i 2}$ amount of power to the affected AC grid by preserving the following constraints:

$$
\sum_{j=1}^{r} R_{g j i} \geq \Delta P_{c i 2}
$$

Hence, (20) can be rewritten as

$$
\sum_{j=1}^{r} R_{g j i} \leq 2 \sum_{j=1}^{r} v_{g j i} \frac{H_{m i} \Delta f_{i}}{\Delta P_{c i 2}}
$$

$$
R_{T i} \leq 2 v_{T i} \frac{H_{m i} \Delta f_{i}}{\Delta P_{c i 2}}
$$

In (23), $R_{T i}$ and $v_{T i}$ are the total primary reserve and the maximum ramp rate of the $i$ th asynchronous grid. These are assumed to be constant after the contingency in order to reduce the associated complexity in the analysis.

Therefore, for maximum permissible frequency deviation, the maximum power provided by the asynchronous grid can be determined from (23). This refers to the following relation:

$$
\Delta P_{c i 2 \max }=\frac{2 v_{T i} H_{m i}}{R_{T i}} \Delta f_{i \max }
$$

Consequently, (24) relates the variation of power support with the deviation of frequency. The range of power extraction can be examined by the proximity of frequency deviation $(\Delta f)$ within the maximum allowed frequency excursion. Moreover, the magnitude of power support is regulated with the movement of $\Delta f$. Thereby, $\Delta f$ is another governing factor to measure the proportion of power sharing.

\subsection{Formulation of adaptive droop}

The fixed droop value is revised accordingly to get adaptive in nature to incorporate the frequency characteristics of the grid. Depending on this adaptive droop behaviour, the required power for the grid is shared adaptively by the asynchronous grids.

Utilising the contribution of RoCoF in (19) and frequency deviation in (24) together, total power participation of (10) can be revised as follows:

$$
\begin{aligned}
\Delta P_{c i} & =2 H_{m i} . \Delta \dot{f}_{i}+\frac{2 v_{T i} H_{m i}}{R_{T i}} \Delta f_{i} \\
& =2 H_{m i}\left(\Delta \dot{f}_{i}+\frac{2 v_{T i}}{R_{T i}} \Delta f_{i}\right) \\
& =2 H_{m i} \Delta F_{i}
\end{aligned}
$$

In (25), $\Delta F_{i}=\left(\Delta \dot{f}_{i}+\left(2 v_{T i} / R_{T i}\right) \Delta f_{i}\right)$ is the frequency response characteristics of the supporting asynchronous grids. Therefore, the supplied power of the sending-end asynchronous grid is predominantly dependent on the frequency response characteristics $\left(\Delta F_{i}\right)$.

To determine the optimal power support of the asynchronous grids for its maximum permissible frequency response characteristics, (25) can be expressed as

$$
\Delta P_{c i \max }=2 H_{m i} \Delta F_{i \max }
$$

Now, the constant droop value of the CDC is made adaptive with the inclusion of a variable factor called a factor of proximity. The factor of proximity defines the state of the power contribution with respect to its marginal value. Using (25) and (26), power support from the asynchronous grids can be defined in terms of the proximity factor as given in (27):

$$
\frac{\Delta P_{c i \max }-\Delta P_{c i}}{\Delta P_{c i \max }}=\frac{\Delta F_{i \max }-\Delta F_{i}}{\Delta F_{i \max }}=\alpha
$$

In (27), $\alpha$ is denoted as the factor of proximity ranging from 0 to 1 .

The smaller value of $\Delta F_{i}$ corresponds to a larger value of $\alpha$. This indicates that the higher proportion of power is still available to be shared within its permissible limit. The lower the value of the factor indicates the smaller amount of power to be shared.

On the other hand, the proportion of maximum power support for allowable frequency response characteristics can be determined from (26). This is referred to as the participation factor and denoted by: 


$$
\beta=\frac{\Delta P_{c i \max }}{\sum_{i=1}^{n} \Delta P_{c i \max }}
$$

Therefore, considering the effect of the proximity factor $\alpha$ and participation factor $\beta$, the value of the fixed droop coefficient is modified to the adaptive droop coefficient as follows:

Adaptive droop $=$ Fixed droop $\times n \times \alpha \times \beta$

$$
\begin{aligned}
k_{v i}^{\mathrm{ADC}} & =k_{v i} n \alpha \beta=k_{v i} \cdot n \cdot \frac{\Delta P_{c i \max }-\Delta P_{c i}}{\sum_{i=1}^{n} \Delta P_{c i \max }} \\
& =k_{v i} \cdot n \cdot \frac{\Delta P_{c i \max }-2 H_{m i} \Delta F_{i}}{\sum_{i=1}^{n} \Delta P_{c i \max }}
\end{aligned}
$$

In (29), $k_{v i}^{\mathrm{ADC}}$ is the adaptive droop coefficient that substantially depends on $\Delta F_{i}$ and $n$ (the number of converters equipped with voltage droop controller).

The relation of power versus DC voltage droop controller in (8) and (9) can then be revised with the adaptive droop value as follows:

$$
\begin{gathered}
P_{c}^{*}=P_{c}^{0}-k_{v}^{\mathrm{ADC}}\left(V_{c}^{0}-V_{c}\right) \\
\Delta P_{c i}=-k_{v i}^{\mathrm{ADC}} \Delta V_{c}
\end{gathered}
$$

Finally, the total shared power given in (11) and (12) can be modified as follows:

$$
\begin{gathered}
\Delta P_{\mathrm{s}}=\sum_{i=1}^{n} \Delta P_{c i}=\sum_{i=1}^{n}-k_{v i}^{\mathrm{ADC}} \Delta V_{c}=\sum_{i=1}^{n} F_{i}(\Delta f, \Delta \dot{f}) \\
\Delta P_{c i}=\frac{k_{v i}^{\mathrm{ADC}}}{\sum_{i=1}^{n} k_{v i}^{\mathrm{ADC}}} \Delta P_{\mathrm{s}}
\end{gathered}
$$

It is evident from (32) and (33) that the adaptive droop value contains the information of frequency characteristics of the supporting AC grids by maintaining the necessary constraints. As a result, when the $\mathrm{DC}$ grid demands power from the $\mathrm{AC}$ network by means of power versus DC voltage controller (ADC), instead of supporting equal power, it shares power adaptively in terms of their power sharing capability within permissible frequency limits. Fig. 3 shows the corresponding block diagram of the proposed ADC scheme.

The adaptive nature of the ADC scheme is clearly depicted in Fig. 4. It shows that active power support is inversely proportional to the adaptive droop coefficient and changes proportionately with the increment of system inertia $(H)$. Consistent with the RoCoF, the deviation of frequency also increased with the variation of active power. When the active power support of an asynchronous grid (with lower inertia) reaches to its maximum frequency dynamic limit, the proportion of power share is transferred to other asynchronous grids (with higher inertia) with available frequency limits. Hence, frequency regulation is enhanced without jeopardising the security of the asynchronous grids.

The mechanism of frequency support in the proposed control scheme can be illustrated more precisely by the following sequence of events.

Pre-contingency events:

(i) The inertia constant $H_{m i}$ is continuously estimated by the method explained in [24].

(ii) For the $i$ th asynchronous grid, the total primary reserve $R_{T i}$ and the maximum ramp rate $v_{T i}$ are predefined and these are assumed to be constant before the sending power to the receiving-end asynchronous grid. (iii) The maximum value of frequency dynamic limit $\left(\Delta f_{i \max }\right.$ and $\left.\Delta \dot{f}_{i \text { max }}\right)$ is predefined. Hence, the optimal power participation of the $i$ th asynchronous grid $\Delta P_{c i \text { max }}$ is computed by (26).

Post-contingency events:

(i) Upon the detection of a large disturbance, the frequency deviation $\left(\Delta f_{i}\right)$ is measured using phase locked loop and the corresponding frequency response characteristics $\Delta F_{i}=\left(\Delta \dot{f}_{i}+\left(2 v_{T i} / R_{T i}\right) \Delta f_{i}\right)$ is calculated.

(ii) With the online values of inertia constant $H_{m i}$, the instant power support of the $i$ th asynchronous grid $\Delta P_{c i}$ is computed using (25).

(iii) According to (29), the fixed value of conventional droop coefficient, $k_{v i}$ would be changed with the variation of $\Delta P_{c i}$ that substantially depends on $\Delta F_{i}$.

\section{Results and discussion}

To validate the effectiveness of the proposed control scheme, a three-terminal MMC-MTDC system integrated into three asynchronous $\mathrm{AC}$ grids is used in this paper. The comprehensive analysis results are given in this section. The single-line diagram of the test system is presented in Fig. 5.

Grid-1 is a prevalent power system model reported in [25] with substantial modifications. The network consisting of three generators and two loads represents the England and Scotland power system. The total generation capacity of the system is 26,600 MVA with 22,750 MW consumption. All the generators are modelled with steam turbine governors (gov_TGOV1) and automatic voltage regulators (avr_ESDC1A) including local power system stabilizers.

Grid-2 is based on the nine-bus power system network presented in [26] with three generators and loads. Total generation

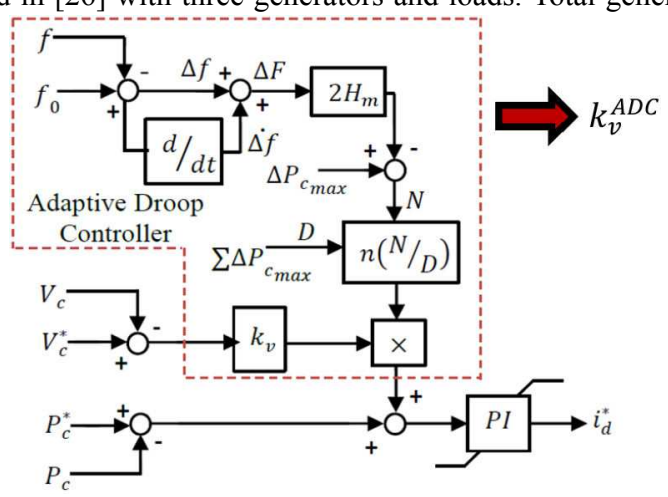

Fig. 3 ADC scheme

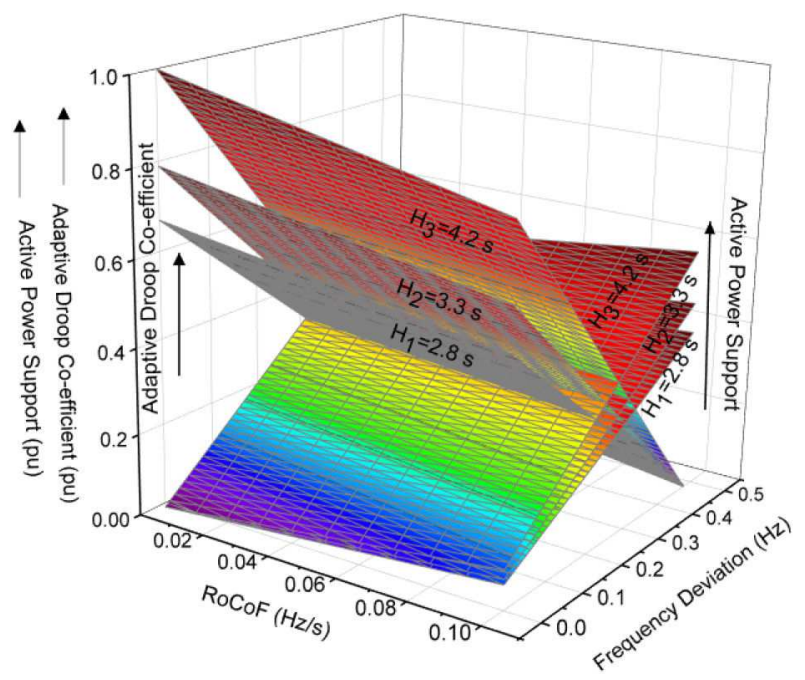

Fig. 4 Adaptive droop characteristics of $A D C$ scheme with different system inertia 


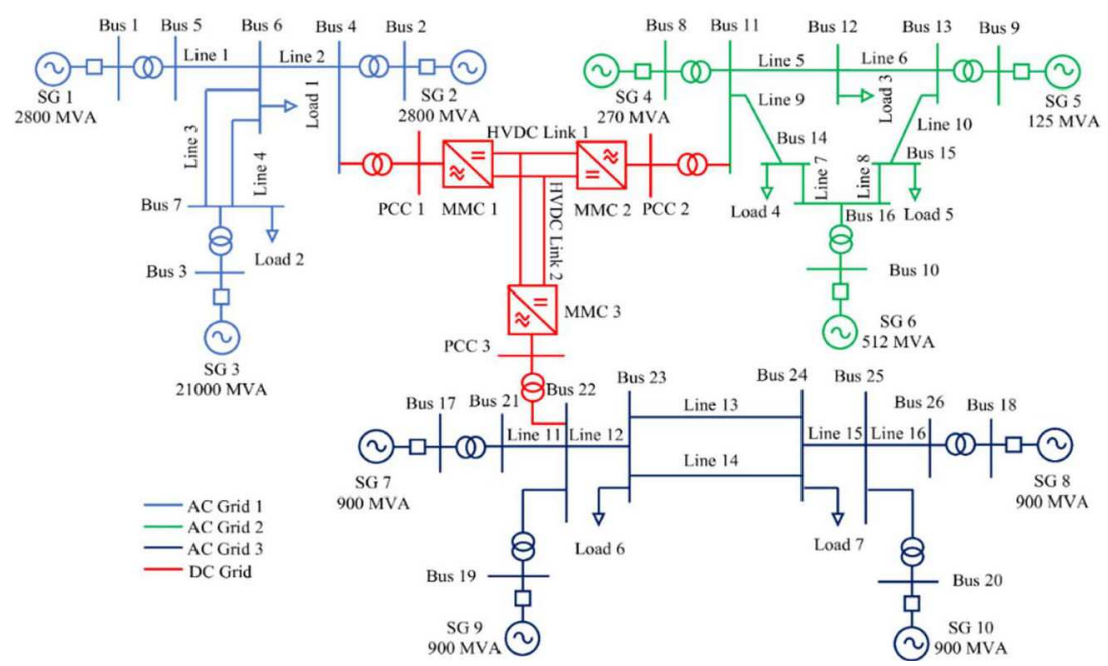

Fig. 5 Single-line diagram of AC/MTDC interconnected system

Table 1 Parameters of MMC system

\begin{tabular}{lc}
\hline Item & Value \\
\hline nominal AC voltage, $\mathrm{kV}$ & 551 \\
fundamental frequency, $\mathrm{Hz}$ & 50 \\
nominal DC voltage, $\mathrm{kV}$ & \pm 500 \\
rated MMC capacity, MVA & 800 \\
SMs per arm & 200 \\
$\mathrm{SM}$ capacitance, $\mu \mathrm{F}$ & 10,000 \\
arm inductance, $\mathrm{mH}$ & 60 \\
arm resistance, $\Omega$ & 0.006 \\
$\mathrm{DC}$ cable length, $\mathrm{km}$ & 50 \\
DC cable resistance, $\Omega / \mathrm{km}$ & 0.011 \\
DC cable inductance, $\mathrm{mH} / \mathrm{km}$ & 0.519 \\
\hline
\end{tabular}

Table 2 Control parameters

\begin{tabular}{lcc}
\hline Item & Parameters, pu & Value \\
\hline MMC-1 controller & inner loop proportional gain & 0.25 \\
& inner loop time constant & 0.001 \\
& outer loop proportional gain & 20 \\
& outer loop time constant & 0.6 \\
& frequency dead band & 0.02 \\
MMC-2 controller & frequency droop coefficient & 0.02 \\
& inner loop proportional gain & 0.1 \\
& inner loop time constant & 0.05 \\
& outer loop proportional gain & 15 \\
& outer loop time constant & 0.15 \\
MMC-3 controller & voltage droop coefficient & 20 \\
& inner loop proportional gain & 0.05 \\
& inner loop time constant & 0.1 \\
& outer loop proportional gain & 15 \\
& outer loop time constant & 0.15 \\
& voltage droop coefficient & 20 \\
\hline
\end{tabular}

capacity and load demand of the system is 907 MVA and $315 \mathrm{MW}$, respectively. All the generators are equipped with gov_BPA GG and avr_IEEET1 type governors and exciters, respectively [27].

Grid-3 represents the two-area power system described in [28]. This system comprises four generators with 3600 MVA total capacity and $2734 \mathrm{MW}$ of total demand. All four generators are modelled with automatic voltage regulators (avr_ESDC1A), steam turbine governors (gov_TGOV1) and power system stabilisers (pss_STAB1).

All three asynchronous $\mathrm{AC}$ grids are interconnected via an MTDC system comprising three MMCs rated with $800 \mathrm{MW}$ and $\pm 500 \mathrm{kV}$ HVDC link. The parameters of the MMC-MTDC system

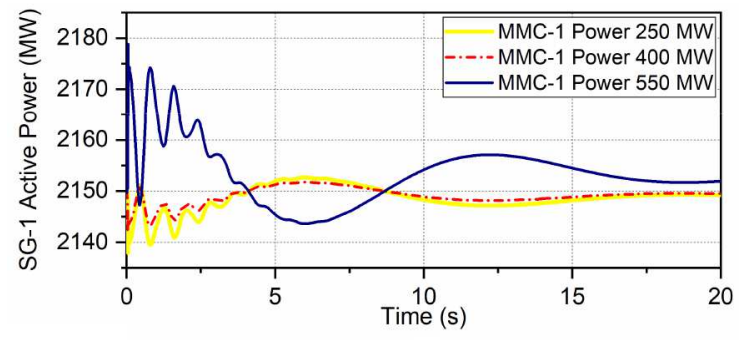

a
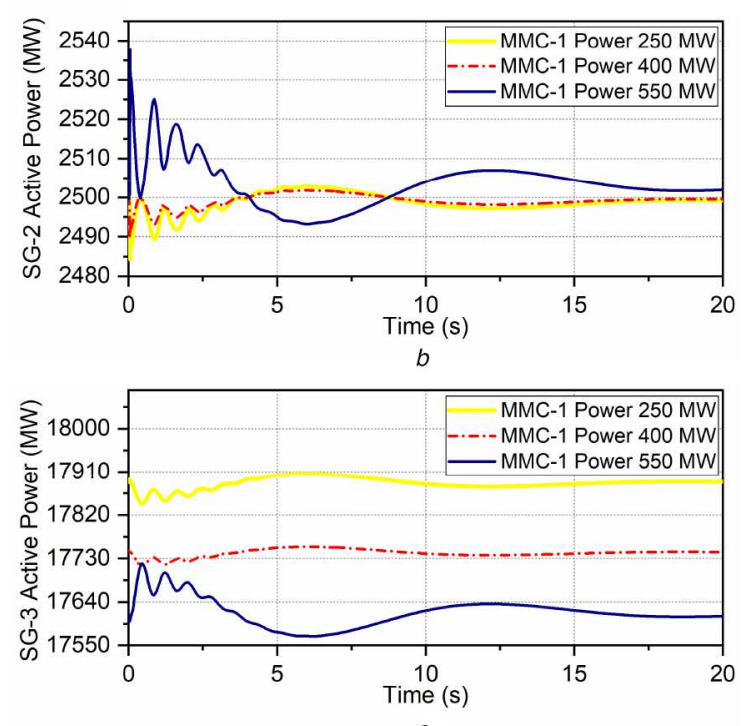

Fig. 6 Grid-1 active power for MMC-1 scheduled power of 250, 400, and $550 \mathrm{MW}$

(a) Active power of SG-1 (MW), (b) Active power of SG-2 (MW), (c) Active power of SG-3 (MW)

are given in Table 1. All control parameters of the MMCs are given in Table 2. The test system is developed and analysed in DIgSILENT PowerFactory [29].

For three different scheduled power of MMC-1 converter (250, 400 and $550 \mathrm{MW}$ ), the steady-state power response of Grid-1 generators is presented in Figs. $6 a-c$. It is explicit from Fig. $6 c$ that the power contribution of SG-3 is gradually reduced with the augmentation of MMC-1 scheduled power. However, the power variation of SG-1 and SG-2 is very small as shown in Figs. $6 a$ and $b$, respectively. Hence, Grid-1 substantially receives the power from the MTDC grid to meet the load demand. In this paper, the first steady-state operating condition is considered for further analysis. 


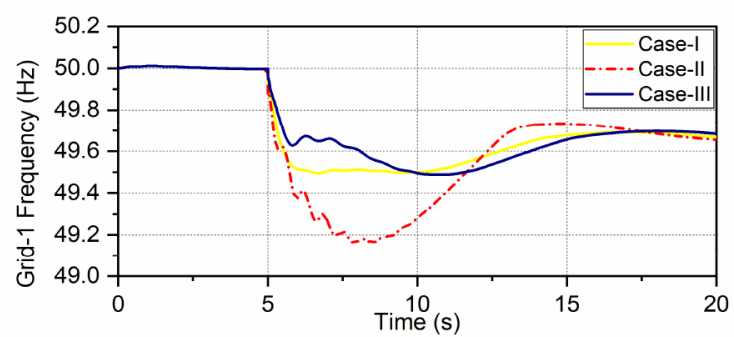

a

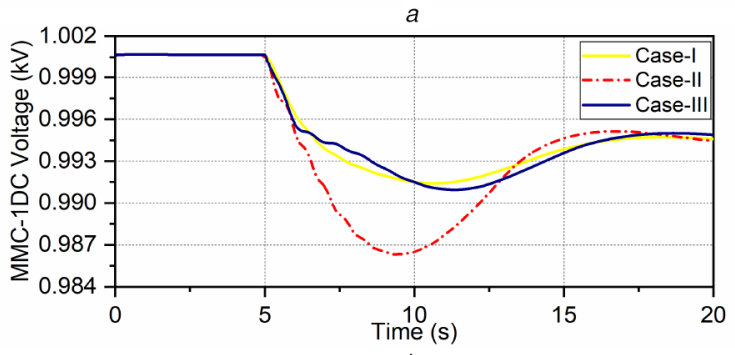

$b$

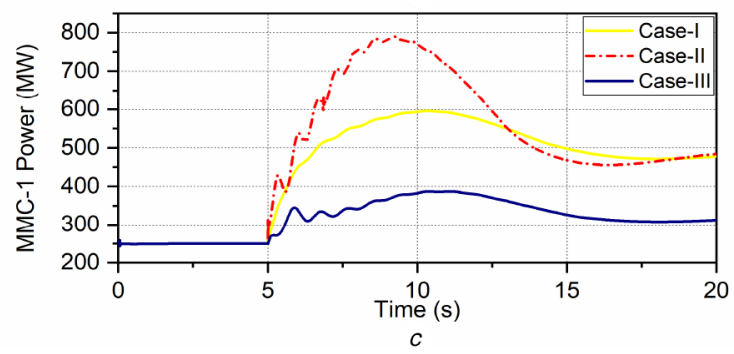

Fig. 7 Simulation results of Case-I, Case-II, and Case-III

(a) Frequency of Grid-1 (Hz), (b) DC voltage of MMC-1 (kV), (c) Active power of MMC-1 (MW)

In the steady state, Grid-1 draws $250 \mathrm{MW}$ power from the MTDC grid via MMC-1 station, while the rest of the power is supplied by the synchronous machines in Grid-1. At the same time, the MTDC grid receives the power of 50 and $200 \mathrm{MW}$ from MMC-2 and MMC-3 supplied by Grid-2 and Grid-3, respectively.

\subsection{Analysis of frequency response characteristics}

To create frequency excursion in Grid-1 the following disturbances are considered:

(i) Case-I: Extra load of 25\% at Load-1 and 10\% at Load-2 are switched on at $t=5 \mathrm{~s}$.

(ii) Case-II: SG-1 is switched off at $t=5 \mathrm{~s}$.

(iii) Case-III: Outage of MMC-2, and 13\% extra load at Load-2 is switched on at $t=5 \mathrm{~s}$.

For the prior mentioned cases, the post-disturbance responses of DC voltage variations, active power support of MMC-1, and frequency deviations of Grid-1 are presented in Figs. $7 a-c$, respectively. From these figures, it is evident that the Grid-1 experienced the lowest frequency nadir for Case-II.

5.1.1 Case-I (increased load): In this case study, the grid disturbance is introduced by increasing $25 \%$ demand in Load- 1 and $10 \%$ demand in Load- 2 at $5 \mathrm{~s}$. Followed by the disturbance, Grid-1 experiences a significant frequency excursion, $49.49 \mathrm{~Hz}$ as shown in Fig. $7 a$. The limit of excursion satisfies the condition $(\Delta f>0.5)$ to switch the supplementary controller from power droop (DC voltage versus power) to frequency droop (DC voltage versus frequency) in MMC-1 station. Utilising the value of frequency droop calculated by (6) and (7), the DC voltage deviation is found to be around $0.8 \%$, which is almost negligible compared to maximum permissible limit ( 5\%) [30]. The MMC-2 and MMC-3 stations respond accordingly with the voltage variation of the MTDC grid to facilitate voltage droop (power versus DC voltage) controller embedded in it.
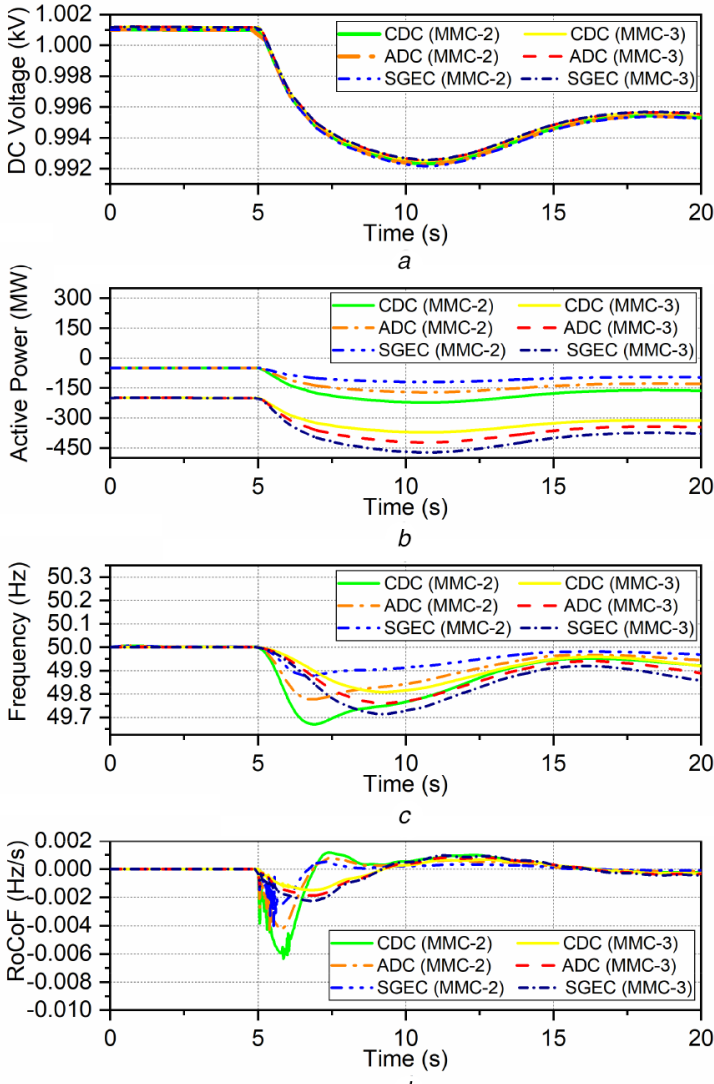

Fig. 8 Simulation results (Case-I)

(a) DC voltage of MMC-2,3 (kV), (b) Active power of MMC-2,3 (MW), (c) Frequency of Grid-2,3 (Hz), (d) RoCoF of Grid-2,3 (Hz/s)

Figs. $8 a-d$ illustrate the responses of DC voltage deviation, active power support, and frequency response characteristics for $\mathrm{CDC}, \mathrm{ADC}$, and SGEC strategies, respectively. In the CDC scheme, MMC-2 and MMC-3 release equal amount of extra power $(113 \mathrm{MW})$ in response to the DC voltage deviation. Consequently, the frequency response of Grid-2 and Grid-3 deviates (Grid-2: $\Delta f=0.329 \mathrm{~Hz}, \Delta \dot{f}=-0.006 \mathrm{~Hz} / \mathrm{s}$ and Grid-3: $\Delta f=0.192 \mathrm{~Hz}$, $\Delta \dot{f}=-0.001 \mathrm{~Hz} / \mathrm{s}$ ) considerably. On the other hand, in the SGEC strategy, MMC-2 and MMC-3 provide 48 and $178 \mathrm{MW}$ of extra power, respectively. Hence, the frequency response characteristics of the supporting grids are summarised as: Grid-2: $\Delta f=0.123 \mathrm{~Hz}$, $\Delta \dot{f}=-0.003 \mathrm{~Hz} / \mathrm{s} \quad$ and Grid-3: $\quad \Delta f=0.285 \mathrm{~Hz}$, $\Delta \dot{f}=-0.002 \mathrm{~Hz} / \mathrm{s}$. However, the strategy in SGEC is mainly dependent on the scheduled power of the converter without considering the load burden of asynchronous grids. For delivering the same amount of power with $\mathrm{CDC}$, the frequency dynamics of Grid-2 is affected significantly.

To get rid of this problem, ADC is utilised with the frequency response constraints. With the help of (26), the maximum power participation of Grid-2 and Grid-3 is found to be 35 and $65 \%$, respectively, for maximum frequency dynamic limits $(\Delta f=0.485 \mathrm{~Hz}, \Delta \dot{f}=-0.1 \mathrm{~Hz} / \mathrm{s})$. Before the disturbance, the value of proximity factor is 1 (unity) for both grids, which represents the maximum power sharing capability after the contingency.

With the online values of power participation $(\beta)$ and proximity factor $(\alpha)$, the constant droop value of $k_{v}$ keeps on changing according to (29). Hence, for balancing power in the MTDC grid, Grid-3 is supposed to share more power than the Grid-2 within frequency excursion limits. Therefore, Grid-2 reduced its shared power to $80 \mathrm{MW}$, whereas Grid-3 increased the power to $146 \mathrm{MW}$.

Eventually, frequency responses of these supporting grids enhance significantly with the ADC scheme (Grid-2: $\Delta f=0.224 \mathrm{~Hz}, \Delta \dot{f}=-0.004 \mathrm{~Hz} / \mathrm{s}$ and Grid-3: $\Delta f=0.240 \mathrm{~Hz}$, 
Table 3 Comparison of CDC, ADC and SGEC strategies for Case-I

\begin{tabular}{lccccc}
\hline Converter (Grid) & Controller & $\Delta V, \mathrm{kV}$ & $\Delta P, \mathrm{MW}$ & $\Delta f, \mathrm{~Hz}$ & $\mathrm{RoCoF}, \mathrm{Hz} / \mathrm{s}$ \\
\hline MMC-2 (Grid-2) & CDC & $0.8 \%$ & 113 & 0.329 & -0.006 \\
& ADC & $0.8 \%$ & 80 & 0.224 & -0.004 \\
MMC-3 (Grid-3) & SGEC & $0.9 \%$ & 48 & 0.123 & -0.003 \\
& CDC & $0.8 \%$ & 113 & 0.192 & -0.001 \\
& ADC & $0.8 \%$ & 146 & 0.240 & -0.002 \\
\hline
\end{tabular}

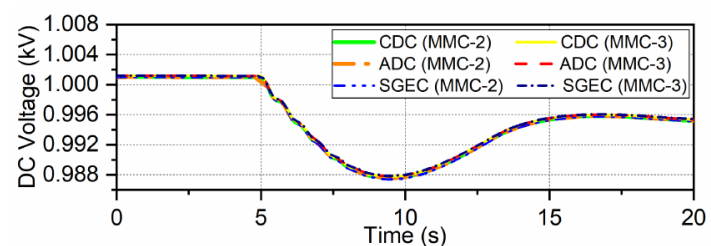

a

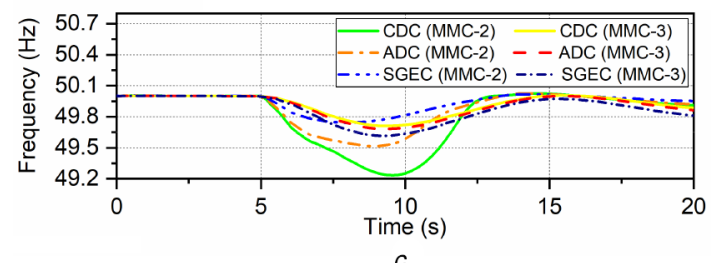

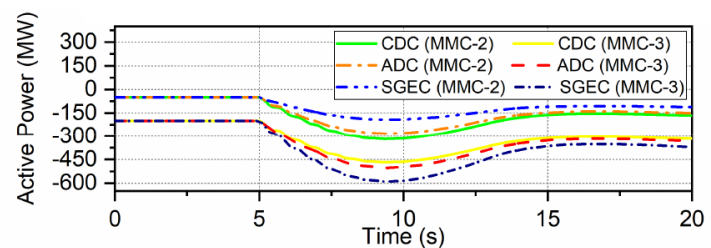

$b$

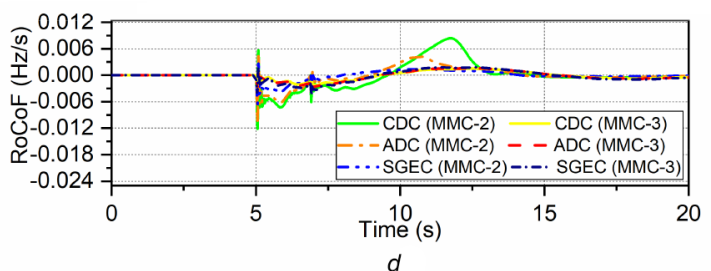

d

Fig. 9 Simulation results (Case-II)

(a) DC voltage of MMC-2,3 (kV), (b) Active power of MMC-2,3 (MW), (c) Frequency of Grid-2,3 (Hz), (d) RoCoF of Grid-2,3 (Hz/s)

Table 4 Comparison of CDC, ADC and SGEC strategies for Case-II

\begin{tabular}{lccccc}
\hline Converter (Grid) & Controller & $\Delta V, \mathrm{kV}$ & $\Delta P, \mathrm{MW}$ & $\Delta f, \mathrm{~Hz}$ & $\mathrm{RoCoF}, \mathrm{Hz} / \mathrm{s}$ \\
\hline MMC-2 (Grid-2) & CDC & $0.8 \%$ & 116 & 0.766 & -0.012 \\
& ADC & $0.8 \%$ & 100 & 0.485 & -0.006 \\
MMC-3 (Grid-3) & SGEC & $1.4 \%$ & 56 & 0.259 & -0.003 \\
& CDC & $0.8 \%$ & 116 & 0.289 & -0.002 \\
& ADC & $0.8 \%$ & 132 & 0.319 & -0.003 \\
\hline
\end{tabular}

$\Delta \dot{f}=-0.002 \mathrm{~Hz} / \mathrm{s})$. Table 3 illustrates the comparison of different simulation results for the CDC, ADC and SGEC schemes.

5.1.2 Case-Il (generator switched-off): In this study, the grid disturbance is encountered by a sudden loss of generation (switch off SG-1) in Grid- 1 at $t=5 \mathrm{~s}$. With this extensive disturbance, the grid frequency deviates largely from 50 to $49.161 \mathrm{~Hz}$ and causes DC voltage deviation (around $0.8 \%$ decrease of nominal value) within the permissible limit as shown in Figs. $7 a$ and $b$.

Figs. 9a-d illustrate the responses of DC voltage deviation, active power support, and frequency response characteristics for the $\mathrm{CDC}, \mathrm{ADC}$, and SGEC strategies, respectively. In the CDC strategy, the post-contingency additional power of MMC-1 (232 MW) is equally supplied by Grid-2 and Grid-3. This causes a permissible frequency deviation of $0.289 \mathrm{~Hz}$ in Grid-3. However, power support from Grid-2 results in a major frequency deviation of $0.766 \mathrm{~Hz}$ that exceeds the boundary limit $(0.485 \mathrm{~Hz})$. Frequency response characteristics of the supporting grids are summarised as: Grid-2: $\quad \Delta f=0.766 \mathrm{~Hz}, \quad \Delta \dot{f}=-0.012 \mathrm{~Hz} / \mathrm{s} \quad$ and Grid-3: $\Delta f=0.289 \mathrm{~Hz}, \Delta \dot{f}=-0.002 \mathrm{~Hz} / \mathrm{s}$. In the SGEC strategy, the proportion of power support remains almost the same ( $\sim 22$ and $\sim 78 \%$ ) with the scheduled output power of the converters and regulates the frequency with the following frequency response characteristics: Grid-2: $\Delta f=0.259 \mathrm{~Hz}, \Delta \dot{f}=-0.003 \mathrm{~Hz} / \mathrm{s}$ and Grid-3: $\Delta f=0.385 \mathrm{~Hz}, \Delta \dot{f}=-0.003 \mathrm{~Hz} / \mathrm{s}$.

On the other hand, in the ADC strategy, after reaching its maximum limit (i.e. proximity factor is 0 ), Grid-2 stops sharing power and the rest of the burden is shared by Grid-3. Hence, instead of $116 \mathrm{MW}$, Grid-2 delivers $100 \mathrm{MW}$ adaptively and the remaining $14 \%$ demand is supplied by Grid-3. Therefore, the frequency responses of Grid-2 are substantially enhanced.

Frequency response characteristics with the ADC strategy are summarised as: Grid-2: $\Delta f=0.485 \mathrm{~Hz}, \Delta \dot{f}=-0.006 \mathrm{~Hz} / \mathrm{s}$ and Grid-3: $\quad \Delta f=0.319 \mathrm{~Hz}, \quad \Delta \dot{f}=-0.003 \mathrm{~Hz} / \mathrm{s}$. The simulation results of the CDC, ADC, and SGEC schemes are also compared and summarised in Table 4.

5.1.3 Case-III (converter outage): In this case, the MTDC grid is disturbed after disconnecting MMC-2 station at $t=5 \mathrm{~s}$. At the same time, $13 \%$ demand at Load-1 is increased in Grid-1. Hence, the power contribution from Grid-2 (100 MW) is interrupted. The CDC and SGEC strategies are failed to regulate this power imbalance. Thus, the total supplementary power of MMC-1 is reduced to $310 \mathrm{MW}$, which is supplied only by MMC-3.

The proposed ADC scheme can resolve the issue by adjusting the droop value. Figs. $10 a-d$ illustrate the corresponding responses of DC voltage deviation, active power support, and frequency response characteristics, respectively, for $\mathrm{CDC}$, ADC, and SGEC strategies. In the ADC scheme, the MMC-3 station adopts the deficit power of $100 \mathrm{MW}$ caused by the outage of MMC-2 and delivers $410 \mathrm{MW}$ power in total without jeopardising the security of Grid-3. The simulation results are compared and summarised in Table 5, which depicts the superiority of the ADC scheme for regulating imbalance power.

\subsection{Analysis of large disturbance rotor angle stability}

Several case studies have been carried out to further investigate the implication of the proposed controller on the large disturbance rotor angle stability of the system. Figs. $10 a-c$ illustrate the rotor 

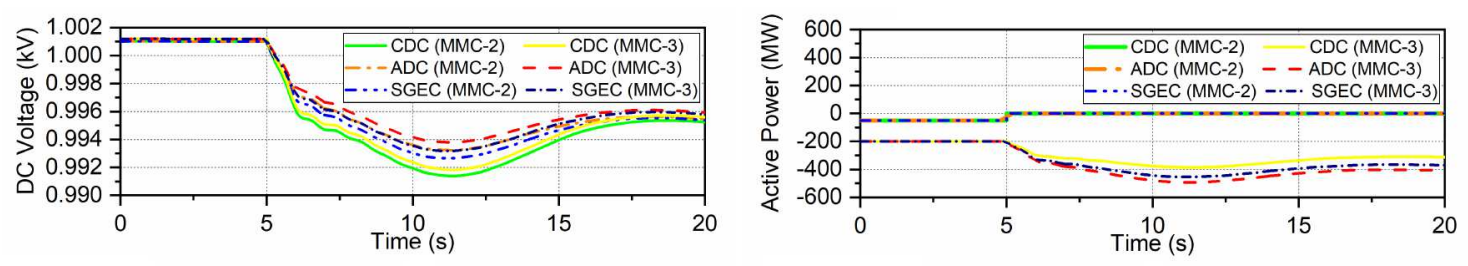

a
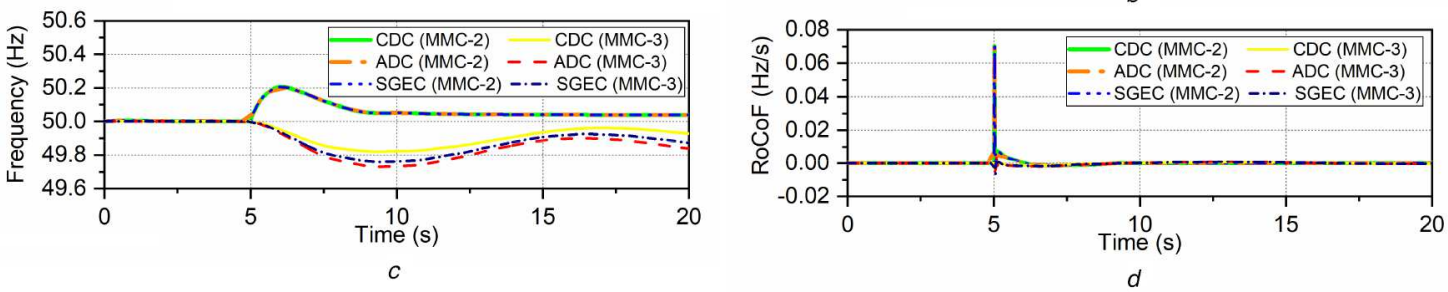

Fig. 10 Simulation results (Case-III)

(a) DC voltage of MMC-2,3 (kV), (b) Active power of MMC-2,3 (MW), (c) Frequency of Grid-2,3 (Hz), (d) RoCoF of Grid-2,3 (Hz/s)

Table 5 Comparison of CDC, ADC and SGEC strategies for Case-III

\begin{tabular}{lccccc} 
Converter (Grid) & Controller & $\Delta V, \mathrm{kV}$ & $\Delta P, \mathrm{MW}$ & $\Delta f, \mathrm{~Hz}$ & $\mathrm{RoCoF}, \mathrm{Hz} / \mathrm{s}$ \\
\hline MMC-2 (Grid-2) & CDC & $0.7 \%$ & 0 & -0.21 & 0.060 \\
& ADC & $0.7 \%$ & 0 & -0.21 & 0.060 \\
MMC-3 (Grid-3) & SGEC & $0.8 \%$ & 0 & -0.21 & 0.070 \\
& CDC & $0.7 \%$ & 110 & 0.180 & -0.003 \\
& ADC & $0.7 \%$ & 210 & 0.269 & -0.004 \\
\hline
\end{tabular}
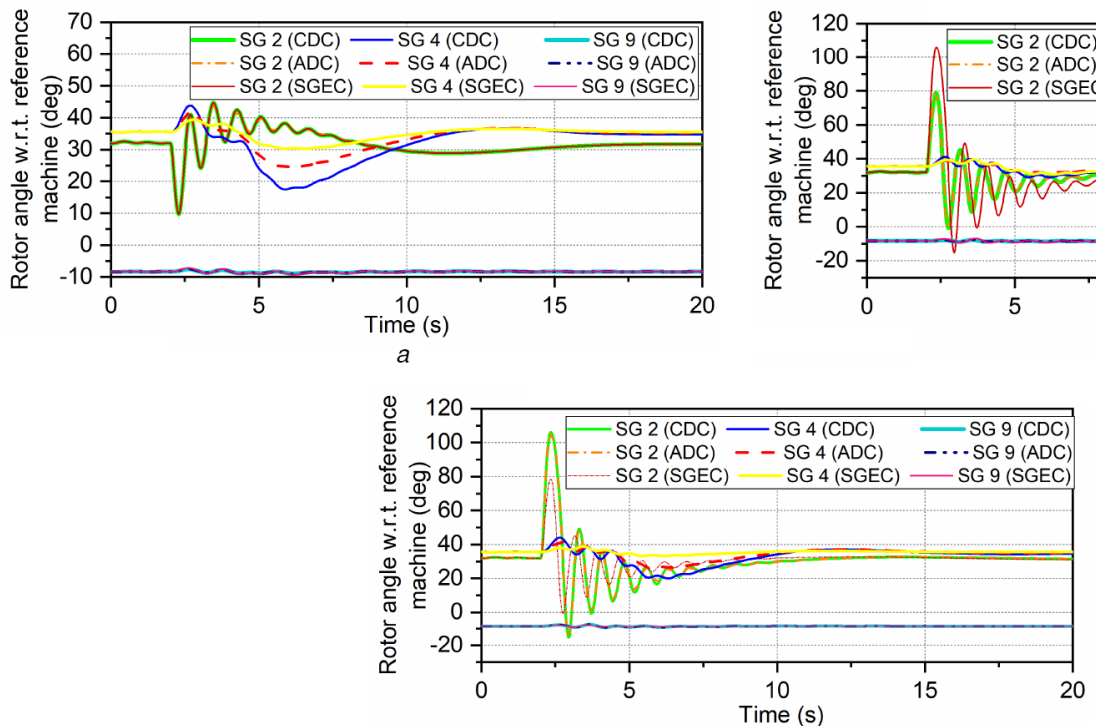

$c$

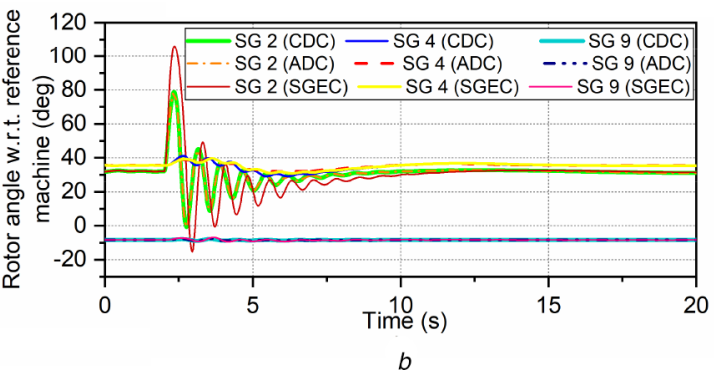

Fig. 11 Rotor angle deviation w.r.t. reference machine

(a) Bus-7 fault for $80 \mathrm{~ms}$ - Case-a, (b) Bus-5 fault for $100 \mathrm{~ms}$ - Case-b, (c) Bus-4 fault for $120 \mathrm{~ms}$ - Case-c

angle deviation of synchronous generators with respect to reference machines for three different cases. To avoid repetition, the single generator from all AC grids (SG-2 from Grid-1, SG-4 from Grid-2, and SG-9 from Grid-3) is outlined in Fig. 11.

Case-a is formulated by introducing a solid three-phase shortcircuit fault at bus- 7 for $80 \mathrm{~ms}$. From the simulation results in Fig. $11 a$, it is observed that the rotor angle deviation of SG-4 shows lower oscillation with SGEC and ADC strategies. Moreover, in the ADC scheme, the maximum rotor swing of SG-4 is reduced to $41.8^{\circ}$ as compared to $45^{\circ}$ with the CDC. However, it is worth noting that the equilibrium points of the pre-fault and post-fault rotor angles do not differ significantly.

In Case-b and Case-c, the solid three-phase short-circuit fault is performed at bus- 5 for $100 \mathrm{~ms}$ and bus- 4 for $120 \mathrm{~ms}$, respectively. Figs. $11 b$ and $c$ show the corresponding responses of generator rotor angles with respect to reference machines. It can be seen from
Fig. $11 b$ that the rotor angle deviations of the generators are almost similar for both the CDC and ADC. However, the maximum rotor swing of $105.8^{\circ}$ is observed in SG-2 for the SGEC strategy. On the other hand, Fig. $11 c$ shows that the post-contingency rotor angle of SG-2 increased sharply and reached its maximum rotor swing of $105.2^{\circ}$ for both the CDC and ADC strategies. The rotor angle of SG-2 is oscillating up to $6 \mathrm{~s}$ and reached to the steady state after 8 s. However, with the ADC strategy SG-4 shows little oscillations compared to the $\mathrm{CDC}$ strategy. The post-contingency rotor angle of SG-7 is very close to its pre-contingency rotor angle for all these cases. Hence, minimal oscillation is developed in SG-7 which died out quickly after the fault clearance. 


\section{Conclusions}

This paper presents an ADC scheme for a mixed AC/DC system connecting multiple AC grids. The scheme enables the asynchronous $\mathrm{AC}$ grids to participate in the primary frequency regulation. Under the major grid disturbance, MMC station adjusts the power injection by changing the voltage droop coefficient adaptively depending on the frequency stability margin of adjacent AC grids. Case studies in a modified multi-machine power system demonstrate the efficacy of the proposed approach to share the asynchronous grid primary reserves without violating the limits in the AC/DC system. Simulation results also reveal the significant improvement of frequency response characteristics and rotor angle stability of the AC systems. The radial MTDC system without DC breakers has been used in this work to validate the effectiveness of the proposed method. The effect of a more complex DC grid with $\mathrm{DC}$ breakers on frequency regulation of $\mathrm{AC}$ systems will be studied in the future.

\section{References}

[1] Martinez Sanz, I., Judge, P.D., Spallarossa, C.E., et al.: 'Dynamic overload capability of VSC HVDC interconnections for frequency support', IEEE Trans. Power Syst., 2017, 32, (4), pp. 1544-1553

[2] McNamara, P., Milano, M.: 'Model predictive control based AGC for multi terminal HVDC connected AC grids', IEEE Trans. Power Syst., 2018, 33, (1), pp. $1036-1048$

[3] Wen, Y., Chung, C.Y., Ye, X.: 'Enhancing frequency stability of asynchronous grids interconnected with HVDC links', IEEE Trans. Power Syst., 2018, 33, (2), pp. $1800-1810$

[4] Haileselassie, T.M., Uhlen, K.: 'Primary frequency control of remote grids by multi-terminal HVDC'. IEEE Power and Energy Society General Meeting (PESGM), Minneapolis, USA, 2010

[5] Papadogiannis, K., Hatziargyriou, N.: 'Optimal allocation of primary reserve services in energy markets', IEEE Trans. Power Syst., 2004, 19, (1), pp. $652-$ 659

[6] Dai, J., Phulpin, Y., Sarlette, A., et al.: 'Coordinated primary frequency control among non-synchronous systems connected by a multi-terminal highvoltage direct current grid', IET Gener. Transm. Distrib., 2012, 6, (2), pp. 99voltage 108

[7] Mauricio, J.M., Marano, A., Gomez-Exposito, A., et al.: 'Frequency regulation contribution through variable-speed wind energy conversion systems', IEEE Trans. Power Syst., 2009, 24, (1), pp. 173-180

[8] Liu, H., Chen, Z.: 'Contribution of VSC-HVDC to frequency regulation of power systems with offshore wind generation', IEEE Trans. Energy Convers., 2015, 30, (3), pp. 918-926

[9] Bianchi, F.D., Dominguez-Garcia, J.L.: 'Coordinated frequency control using MT-HVDC grids with wind power plants', IEEE Trans. Sustain. Energy, 2016, 7, (1), pp. 213-220

[10] Adeuyi, O.D., Cheah-Mane, M., Liang, J., et al.: 'Fast frequency response from offshore multi-terminal VSC-HVDC schemes', IEEE Trans. Power Deliv., 2017, 32, (6), pp. 2442-2452
[11] Kou, P., Liang, D., Wu, Z., et al.: 'Frequency support from a DC-grid offshore wind farm connected through HVDC link: A communication free approach', IEEE Trans. Energy Convers., 2018, 33, (3), pp. 1297-1310

[12] Papangelis, L., Debry, M.-S., Panciatici, P., et al.: 'Coordinated supervisory control of multiterminal HVDC grids: a model predictive approach', IEEE Trans. Power Syst., 2017, 32, (6), pp. 4673-4683

[13] Guan, M., Cheng, J., Wang, C., et al.: 'The frequency regulation scheme of interconnected grids with VSC-HVDC links', IEEE Trans. Power Syst., 2017, 32, (2), pp. 864-872

[14] Andreasson, M., Wiget, R., Dimarogonas, D.V., et al.: 'Distributed frequency control through MTDC transmission systems', IEEE Trans. Power Syst., 2017, 32, (1), pp. 250-260

[15] Vennelaganti, S.G., Chaudhuri, N.R.: 'Selective power routing in MTDC grids for inertial and primary frequency support', IEEE Trans. Power Syst., 2018, 33, (6), pp. 7020-7030

[16] Wang, W., Li, Y., Cao, Y., et al.: 'Adaptive droop control of VSC-MTDC system for frequency support and power sharing', IEEE Trans. Power Syst., 2018, 33, (2), pp. 1264-1274

[17] Shah, R., Preece, R., Barnes, M.: 'Dual-loop primary frequency regulation controller for VSC-HVDC system'. 12th IEEE PES PowerTech Conf., Manchester, UK, 2017

[18] Luo, X., Wang, J., Wojcik, J.D., et al.: 'Review of voltage and frequency grid code specifications for electrical energy storage applications,' Energies, 2018, 11, (5), pp. 1-26

[19] Roberts, C.: 'Review of international grid codes' (ERNEST Orlando Lawrence Berkeley National Laboratory, USA, 2018)

[20] ENTSO-E: 'Rate of change of frequency (ROCOF) withstand capability', 2017

[21] Zhu, J., Booth, C.D., Adam, G.P., et al.: 'Inertia emulation control strategy for VSC-HVDC transmission systems', IEEE Trans. Power Syst., 2013, 28, (2) pp. $1277-1287$

[22] Leon, A.E.: 'Short-term frequency regulation and inertia emulation using an MMC-based MTDC system', IEEE Trans. Power Syst., 2018, 33, (3), pp. 2854-2863

[23] Wen, Y., Li, W., Huang, G., et al.: 'Frequency dynamics constrained unit commitment with battery energy storage', IEEE Trans. Power Syst., 2016, 31, (6), pp. 5115-5125

[24] Zhang, J., Xu, H.: 'Online identification of power system equivalent inertia constant', IEEE Trans. Ind. Electron., 2017, 64, (10), pp. 8098-8107

[25] Anaya-Lara, O., Hughes, F.M., Jenkins, N., et al.: 'Influence of windfarms on power system dynamic and transient stability', Wind Eng.., 2006, 30, (2), pp. $107-127$

[26] Anderson, P.M., Fouad, A.A.: 'Power system control and stability' (IEEE Press, Piscataway, NJ, USA, 1993)

[27] Demetriou, P., Asprou, M., Quirós-Tortós, J., et al.: 'Dynamic IEEE test systems for transient analysis', IEEE Syst. J., 2015, PP, (99), pp. 1-10

[28] Kundur, P.: 'Power system stability and control' (McGraw-Hill, Inc, New York, USA, 1994)

[29] DIgSILENTGmbH: 'DIgSILENT power factory V 2018 SP1- user manual' (DIgSILENTGmbH, Gomaringen, Germany, 2018)

[30] Akkari, S., Prieto-Araujo, E., Dai, J., et al.: 'Impact of the DC cable models on the SVD analysis of a multi-terminal HVDC system'. Proc. of 2016 Power Systems Computation Conf., Genova, Italy, 2016, pp. 1-6 